\title{
El agalma de Roma
}

\author{
Roma | Alfonso Cuarón| 2018
}

\section{Iara Suárez*}

Universidad Nacional de La Plata, Argentina

Recibido: 19 de julio 2019; aceptado: 4 de noviembre 2019

\begin{abstract}
Resumen
En el presente artículo se trabaja la película Roma de Alfonso Cuarón (2018), inspirada en la infancia del director y en las mujeres que lo criaron. En este film,una mujer de la aristocracia mejicana y su empleada se enfrentan a circunstancias angustiosas e inventan un saber hacer allí prescindiendo de los hombres. Tomando como eje esta situación, el presente trabajo se propone pensar cuál es el componente aglutinador en los vínculos sociales contemporáneos, tomando el caso del feminismo como respuesta sintomática al malestar en la cultura, en su diferencia con los vínculos que provienen de las instituciones del Nombre-del-Padre.
\end{abstract}

Palabras Clave: Lazo social | redes | angustia | feminismo | familia | subjetividad

The agalma of Rome

\begin{abstract}
This article works on the film Roma directed by Alfonso Cuarón (2018), inspired by the director's childhood and the women who rised him. In this film, a woman from the Mexican aristocracy and her employee face distressing circunstances and invent a knowledge there, without men. Taking this situation as the axis, the work proposes to think about the agglutinating component in contemporary social link, taking the case of feminism as a symptomatic response to the discontents in the civilization, in its difference within the links that come from The-name-of-Father institutions.
\end{abstract}

Keywords: social links | anxiety | feminism | family | subjectivity

\section{Objeto de culto}

Roma, la película dirigida por el mexicano Alfonso Cuarón (2018) se ha vuelto de culto y muy popular entre quienes participan del movimiento feminista.En el volumen ocho, número tres, de la Revista Journal Ética E Cine(2018-2019), varios autores abordaron distintos aspectos del fanatismo y los diversos lazos sociales que cada comunidad de fanáticos puede proponer.El feminismo, desde nuestro punto de vista no sería tanto una expresión del fanatismo, sino más bien una respuesta sintomática que surge como invención frente al malestar en la cultura actual. Por este motivo hace parte de la serie de temas tratados en el presente número del Journal y mantiene con ellos múltiples puntos de encuentro. Su título, "Pibas. movimientos, identidades, posiciones" enmarca nuestras preguntas: ¿Qué es lo que hace grupo en los diversos movimientos de mujeres? ¿Cómo se definen los lazos entre mujeres en los diferentes discursos?

Quizás el que esta obra circule frecuentemente como objeto agalmático entre quienes integran esas comunidades, nos permita extraer de allí algún saber que colabore con nuestras interpretaciones.

\section{Memorias del director}

"El tiempo y el espacio nos limitan, pero también definen quienes somos, creando vínculos inexplicables con aquellos quefluyen con nosotros por los mismos lugares y almismo tiempo"(https://twitter.com/ROMACuaron). Como decíamos, se trata de un relato inspirado en la infancia del propio Cuarón, acerca del sitio donde creció, sus costumbres, y, principalmente,en las mujeres que lo criaron.Filmada en blanco y negro, esta película establece una distancia temporal con aquella Colonia

* iarasuarez.psi@gmail.com 
Roma de los años '70. Se muestra allí un barrio mexicano, donde viven las familias de clase media alta, en las que operan de algún modo las antiguas estructuras del discurso del amo (Lacan,1969-1970) con sus correspondientes determinaciones que, no obstante, se ven confrontadas a pinceladas muy precisas del malestar en la cultura hoy. En efecto, aparece puesto en evidencia, magníficamente, que no solamente se trata de una decadencia del Nombre-del-Padre y de la posición masculina sino, fundamentalmente, del resto que queda cuando esa devaluación tiene lugar.

Cleo (Yalitza Aparicio), una empleada doméstica de origen mixteco,trabaja junto a una amiga siguiendo las indicaciones de Sofía (Marina de Tavira), la mujer de la casa. Sofía se autoriza en el personaje de su marido médico (Fernando Grediaga) y su saber, para impartirles órdenes.

Poco a poco, la angustia comienza infiltrarse en ellas. El film nos va llevando a través de las escenas más cotidianas a un punto de ruptura, Cleo queda embarazada de su novio Fermín (Jorge Antonio Guerrero), quien se encuentra demasiado lejos de asumir la paternidad. En la pareja de los patrones por su parte, las cosas tampoco van bien: el personaje paterno los abandona sin decir palabra,mientras que el de la madre tiene que vérselas sola con la casa, con los niños y con la verdad inefable del padre. El clima de fondo es el del Otro barrado.

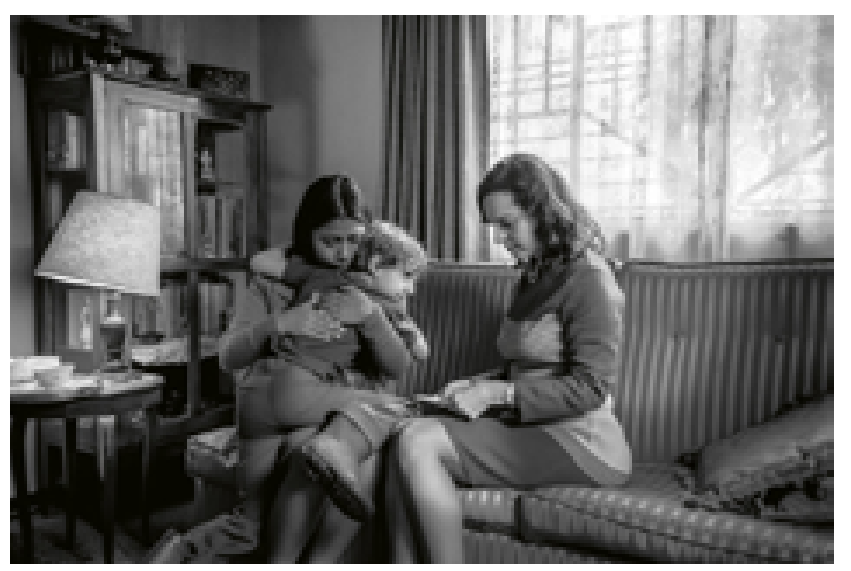

\section{Lazos rizomáticos}

A partir de ese momento, ese en que cada uno de los personajes quedan a merced de su angustia de modo solitario, las mujeres comienzan a articularse entre ellas de una manera muy especial. Es entonces que aparece un nuevo personaje, el de una abuela que se muda a la casa y que acompaña en lo que cada quien necesita sin tener que preguntar. Gracias a ella se establece una red social por la que comienza a circular de cada una para con cada una, todo tipo de recursos e invenciones que se van instalando allí, en ese lugar donde habitaba la angustia. Los intentos por reestablecer el orden anterior fracasan ya que eso era imposible sin el retorno encarnado del padre, tampoco parece interesarles que venga otro hombre en su reemplazo. Es así que Sofía rechaza una propuesta que recibe en navidad. Ahora más bien, la condición para que las cosas funcionen es que no haya hombres intercediendo y que cada una desarrolle bien su juego dentro de esta nueva forma de anudarse. Si en un comienzo, con la presencia de los hombres encarnando el significante amo los lazos eran asimétricos, -patrón -empleado, madre-hijo, esposo-ama de casa -, ahora, dentro de esta nueva configuración, se vuelven horizontales: la empleada habla con su patrona de cosas personales mientras esta le expresa sus sentimientos, la acompaña al médico o la lleva de viaje para superar malos momentos; los niños ya no guardan silencio, hacen preguntas e intervienen con gestos de amor en momentos en que ven en apuros a los adultos, e incluso, a veces, prescinden de las normas. Ahora se autorizan de sí mismos y solo los detiene algo del orden de lo real. Una escena sobre el peligro en el agua nos lo presenta cuando los niños - desoyendo la advertencia materna - se dejan llevar hasta una zona de peligro. Es entonces cuando el deseo se vuelve invención en acto, y Cleo se sumerge arriesgando su vida para salvarlos.

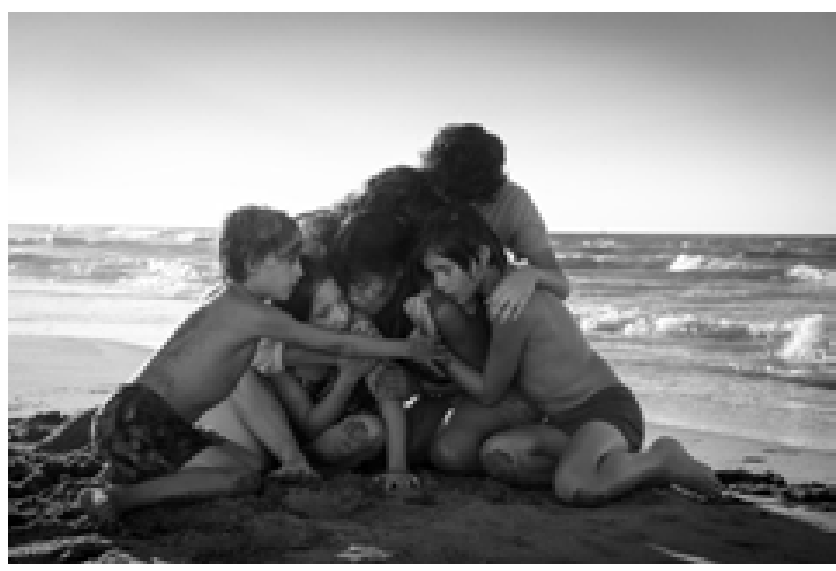

En la actualidad, la familia toma otras formas que aquella ordenada bajo el régimen paterno, y este relato muestra muy bien como la célula madre-hijo puede ser el núcleo de un pequeño conjunto sin límites definidos, que agrega o segrega miembros, que puede expandirse o 
contraerse más o menos erráticamente. El funcionamiento es el de una red, que podríamos pensarla en términos de Deleuze y Guattari (1993) en tanto conjunción rizomática, sin un centro fijo que al que todos los elementos se refieren. Ya no opera la lógica de la Psicología de las masas (Freud, 1921), esto es, un ordenamiento bajo el ideal de la ley y la identificación el rasgo del líder.

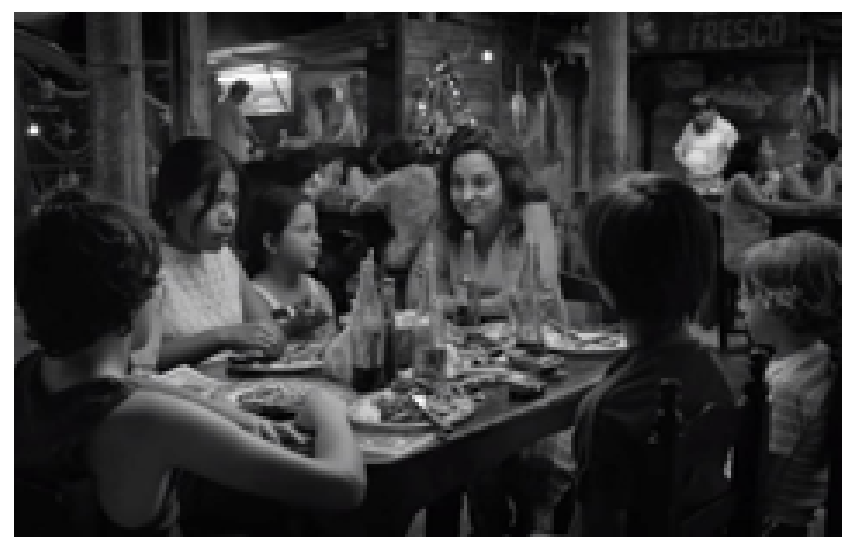

\section{Lo Real del grupo}

En el marco de una conversación con Christine Agnot, Jacques-Alain Miller (2013) plantea:

Hay otro discurso que está en camino de suplantar el discurso único de antaño y eso no se hace sin desga- rros. Digamos que es la innovación en el lugar de la tradición, es la atracción por el porvenir allí donde el peso del pasado encadenaba, más que la jerarquía es la red, se han dado cuenta ya hace unos diez años. Y también es lo femenino que le gana el paso a lo viril. Se conserva un orden, en ese límite inmutable, se inscriben en flujos transformacionales que empujan sus límites. (p. 26)

Eric Laurent (2016) sostiene desde hace algunos años que en la orientación de Jacques Lacan es posible prescindir del papel del rasgo identificador aislado por Freud para leer el régimen del vínculo social contemporáneo. La nueva Massenpsychologie, presidida por la angustia originaria, colectiviza de otro modo al introducir al fantasma como operador y nos permite pensar una articulación entre la subjetividad contemporánea y el corte del sujeto.

¿Cuál sería el modo de colectivizar de la angustia? Para responder esta pregunta, habría que diferenciarlo del lazo que propone la histeria, porque allí hay un síntoma que preside el lazo como lo ilustra magistralmente Freud (1921) con el ejemplo del pensionado de señoritas en Psicología de las masas.

Habría que pensar que si la angustia, además de un afecto que no engaña, es también potencialmente capaz de hacer signo. En efecto, la angustia circunscribe el momento en que los cuerpos se quedan solos, sin el sostén del suelo simbólico. Un signo cuya emergencia plantea el "momento de suspensión del sujeto,en un tiempo en que ya no se sabe dónde está” (Lacan, 1956-1957, p. 228).

\section{Referencias}

Cuarón, A., Rodriguez, G., Celis, N. (productores) y Cuarón, A. (director). (2018). Roma [Cinta cinematográfica]. México: Participant Media y Esperanto Filmoj.

Cuarón, A. [Alfonso]. (16 de agosto de 2018) [Actualización de estado en Twitter]. Recuperado de: https://twitter.com/ROMACua$\mathrm{ron} / \mathrm{status} / 1030081106966601729$ ?s=20

Deluzze, G. \& Guattari, F. (1980). Mil Mesetas. Capitalismo y Esquizofrenia. Valencia: Pre-texto.

Freud,S. (1921). Psicología de las masas y análisis del yo. Obras Completas. Tomo XVIII. México: Amorrortu.

Freud, S. (1930). El malestar en la cultura. Obras Completas. Tomo XXI. México: Amorrortu.

Fanatismos (2018, noviembre). Journal Etica E Cine. Recuperado de: http://journal.eticaycine.org/-Volumen-8-Nro-3-.

Lacan, J. (1956-1957). La relación de objeto. El seminario de Jacques Lacan. Libro 4. Buenos Aires: Paidós.

Lacan, J. (1969-1970). El Reverso del Psicoanálisis. El Seminario de Jacques Lacan. Libro 17. Buenos Aires: Paidós.

Laurent, E. (2016). El reverso de la biopolítica. Buenos Aires: Grama.

Miller, J-A. (2013). Conversación de Jacques- Alain Miller con Christine Agnot en el Teatro Soriano. Feminismos: Variaciones y controversias. Buenos Aires: Grama. 